\title{
Measuring Beach Profiles along a Low-Wave Energy Microtidal Coast, West-Central Florida, USA
}

\author{
Jun Cheng *, Ping Wang and Qiandong Guo \\ School of Geosciences, University of South Florida, Tampa, FL 33620, USA; pwang@usf.edu (P.W.); \\ guo1@mail.usf.edu (Q.G.) \\ * Correspondence: jun@mail.usf.edu
}

Academic Editors: Yongwei Sheng and Jesus Martinez-Frias

Received: 4 July 2016; Accepted: 11 October 2016; Published: 19 October 2016

\begin{abstract}
Monitoring storm-induced dramatic beach morphology changes and long-term beach evolution provides crucial data for coastal management. Beach-profile measurement using total station has been conducted along the coast of west-central Florida over the last decade. This paper reviews several case studies of beach morphology changes based on total-station survey along this coast. The advantage of flexible and low-cost total-station surveys is discussed in comparison to LIDAR (light detection and ranging) method. In an attempt to introduce total-station survey from a practical prospective, measurement of cross-shore beach profile in various scenarios are discussed, including: (1) establishing a beach profile line with known instrument and benchmark locations; (2) surveying multiple beach profiles with one instrument setup; (3) implementation of coordinate rotation to convert local system to real-earth system. Total-station survey is a highly effective and accurate method in documenting beach profile changes along low-energy coasts.
\end{abstract}

Keywords: beach profile; beach erosion; GPS; total-survey station; west-central Florida

\section{Introduction}

Beach erosion is a serious concern for coastal countries throughout the world [1-3]. Beach nourishment has become one of the most commonly used methods to mitigate beach erosion [4]. Physical monitoring of site-specific morphology following nourishments are essential to quantify and predict nourishment performance, gain a more complete understanding of the underlying causes of beach erosion, and improve project design [5]. Various methods have been applied to monitor the beach profile changes, including direct measurement using GPS-RTK(Global Positioning System-Real Time Kinematic) [6], total survey station [7], as well as remote sensing methods such as coastal imaging [8] airborne LIDAR (light detection and ranging) [9], and Unmanned Aerial Vehicles (UAVs) for coastal surveying [10].

With recent development of video-imaging technology, high-performance cameras have been applied to measure nearshore bathymetry and sandbar movements [11]. Generally, the shallow bar crest appears bright in the image due to foam generated by breaking waves, while deeper offshore and trough areas are dark due to the absence of wave breaking [12] ). Therefore, the location of bar crests can be identified from video images due to the close correlation between the main breaker lines with the crests of the sandbars [13]. The great advantage of video imaging is its much higher temporal resolution [14]. However, applications of video imaging along low-energy coast, (e.g., the coast of Gulf of Mexico and the Great Lakes) can be limited because significant waves breaking over sandbars occur only during energetic conditions. No apparent wave breaking occurs over the bar crests under typical conditions, making bar identification via breaking-induced foam practically impossible.

LIDAR is another remote sensing method in coastal morphology survey. Although LIDAR is capable of efficient and reasonably accurate characterization of the beach morphology with high spatial 
resolution [15], such surveys are typically conducted rather infrequently due to high cost and the prior required careful organization [16]. Therefore, LIDAR data tend to have high spatial resolution but poor temporal resolution, which limits their applications for time-series morphology analysis. In addition, turbidities and air bubbles generated by wave breaking can induce large uncertainties for LIDAR measurements, limiting its ability to conduct accurate measurements in the surf zone and over nearshore bars, where frequent changes occur due to active sediment transport. More recently, Unmanned Aerial Vehicles (UAVs) have been developed and widely adopted in beach surveying to obtain high-resolution data at much lower costs than airborne LIDAR $[10,17]$. The disadvantage of UAVs is that they mostly focus on subaerial beach and dune, and therefore the subaqueous portion of the beach is not adequately resolved.

As compared to airborne LIDAR and UAV surveys, total-station surveys using the principles of level and transit represent a much less costly and more feasible survey method. This method has been successfully applied along the low-energy west-central Florida coast, where wave energy is typically low and water is warm [18-21]. A beach profile spaced at $300 \mathrm{~m}$ has been surveyed monthly to bi-monthly since the completion of a beach nourishment project in 2006. Adequate spatial and temporal coverage of beach-profile monitoring is critical for evaluating the performance of the nourishment project [22,23]. Dense spatial coverage is necessary to identify localized erosional hot spots and to ensure the beach nourishment design adequately addresses them. Adequate temporal coverage is needed to accurately document beach changes and to investigate the causes of the changes. In addition, the long-term measured beach profiles allow for reliable estimates of background rates of beach erosion and accretion. Because of the largely unpredictable nature of extreme storms, it is difficult to plan and execute pre-storm field data collection. This problem can be resolved by regularly surveying the beach profiles (e.g., bimonthly or quarterly). The existence of pre-storm data makes it possible to quantify the dramatic morphological impact of storms as well as post storm recovery [24]. The pre-storm profile survey, for instance, was completed two weeks prior to the Tropical Storm Debby in 2012 [21]. The accurate pre- and post-storm beach profiles are valuable for various agencies to estimate the exact volume of sand lost during storms for emergency management [25].

The accuracy of total station surveying has been examined by researchers monitoring beach profile changes [7]. The procedure of conducting the survey, however, has not been well documented. This may prevent a wide application of this survey method, especially when unforeseen complications occur in the field. The purpose of this paper is to provide relatively detailed instructions on conducting beach-profile surveys using total station, using west-central Florida coastal as an example. The paper is organized as follows: the study area is described in Section 2, followed by methodology in Section 3 . The results are presented in Section 4, and the conclusions in Section 5.

\section{Study Area}

The west-central Florida coast is composed of a chain of barrier islands (Figure 1). Sand Key, the longest barrier island along this coast [26], is bound to the north by Clearwater Pass inlet and separated to the south from Treasure Island by John's Pass inlet. Both inlets are mixed-energy with large ebb-tidal deltas [27]. Complex tidal inlet processes have significant influences on beach morphodynamics at the two ends of the barrier island [19,28]. The Sand Key barrier island has an overall shoreline orientation change of $65^{\circ}$ from northwest-facing to southwest-facing beaches, controlled by the antecedent geology (Figure 1). The stabilized wave-dominated migratory Blind Pass [28] inlet separates Treasure Island to the north and Long Key to the south. Long Key is bound to the south by Pass-A-Grille inlet, which is one of the inlets entering the greater Tampa Bay. A large portion of Sand Key, northern and southern end of Treasure Island, as well as northern end of the Long Key have been identified by the Florida Department of Environmental Protection as sites where critical erosion is currently occurring. In order to mitigate the erosion, most of beach has been nourished every six to eight years, with the most recent beach nourishment implemented in 2012. 


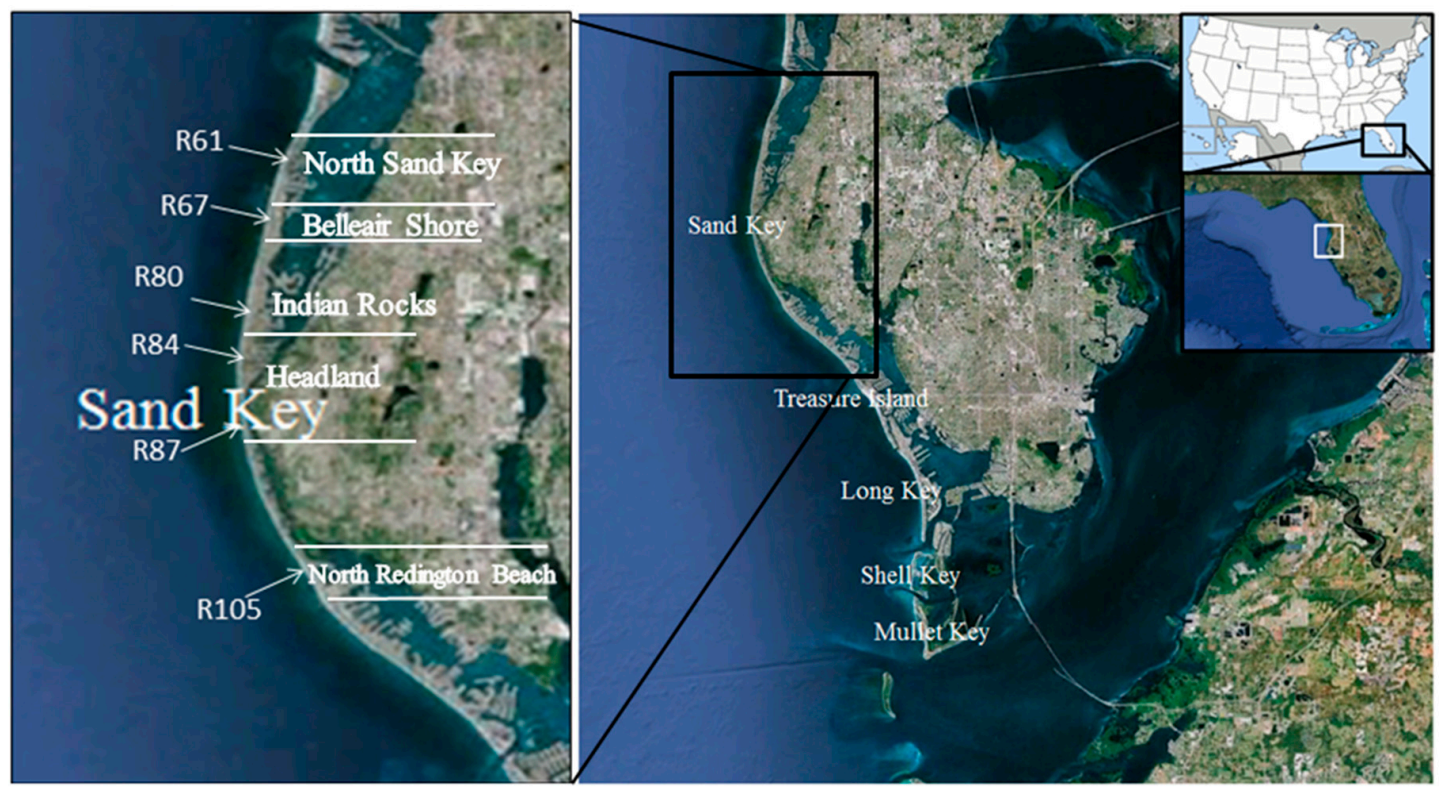

Figure 1. Study area along the coast of west-central Florida.

The west-central Florida coast has a mixed tide regime, with spring tides typically diurnal with a $1 \mathrm{~m}$ tidal range while neap tides are semi-diurnal with a range of about $0.4 \mathrm{~m}$. The wave energy is generally small along the west-central Florida coast, with averaged nearshore significant wave height of less than $0.3 \mathrm{~m}$ [28]. Waves are typically sea-type generated by local winds (Figure 2A). Higher waves are often associated with the passages of cold fronts every couple of weeks during the winter and the occasional passages of tropical storms (Figure 2B). Highly oblique waves generated by the post-frontal northerly winds result in more active southward longshore sediment transport as compared to the northerly transport by the predominant southerly approaching smaller waves. This results in a net annual southward longshore sediment transport [29].

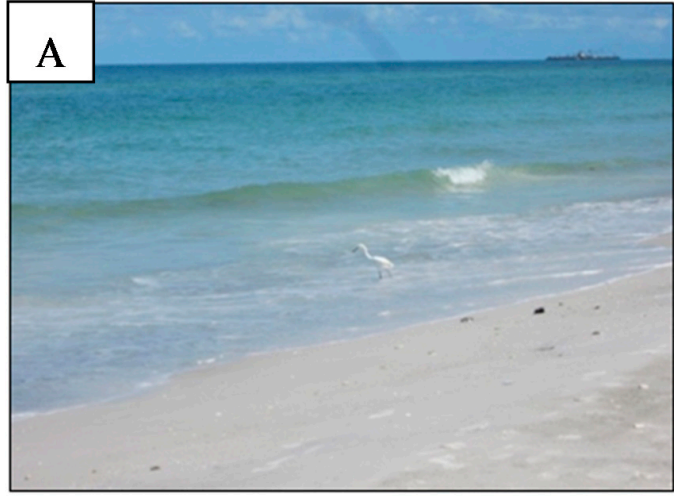

(A)

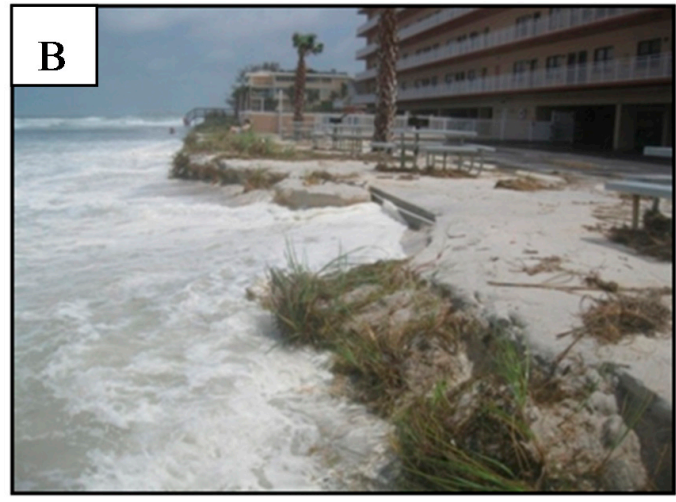

(B)

Figure 2. Study area under normal weather condition (A), as well as under Tropical Storm Debby in 2012 (B).

The track and landfall location of Tropical Storm (TS) Debby was several hundred km north of the study area. However, due to the very large size of the storm and the slow speed of the system, TS Debby induced significant impact to the study area. The high storm waves superimposed on the elevated water level reached the toe of dunes and impacted various sections of seawall (Figure 2B). A character of TS Debby is that the prolonged high wave and strong wind approached from the south, opposite to the net southward longshore transport, for over three days. 
The water level variations measured at NOAA Clearwater Beach Tide Station, about $5 \mathrm{~km}$ north of the study area, illustrated a sustained storm surge of up to $1.0 \mathrm{~m}$ for three days. The peak significant wave height observed at NOAA's NDBC station 42099 approached dominantly from the south with the highest wave reaching nearly $6 \mathrm{~m}$, and a peak wave period of $10 \mathrm{~s}$. Driven by the strong southerly wind, a northward directed longshore current and sediment transport was observed during the storm. In general, TS Debby generated waves that were four to five times higher than the average wave conditions along this coast, and with a much longer wave period of roughly $10 \mathrm{~s}$ versus the average period of $5 \mathrm{~s}$.

\section{Methodology}

\subsection{Measurement under Regular Conditions}

Beach-profile surveying using Topcon total station follows the traditional level-and-transit principle and typically requires three people, with one instrument person, one rod-person responsible for the land part of the survey, and one swimmer for the ocean part of the survey (Figure 3). For this case, a 4-m survey rod is used. It is worth noting that a flat footer is attached to the bottom of the survey rod (Figure 3, left panel), instead of the typical pointy footer. A flat footer prevents the survey rod from sinking into the soft sand to ensure accuracy of the measurement. Field observations indicate that the sharp pointy ends can often penetrate into the sand for 5-10 cm.

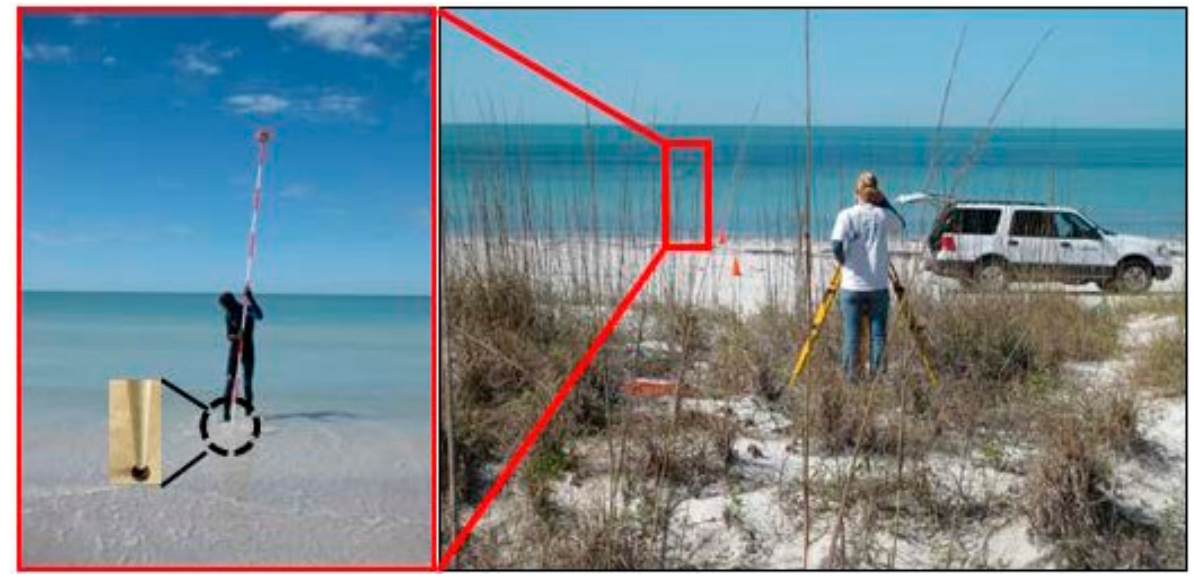

Figure 3. Survey procedures include the use of an electronic level-and-transit total station and a $4 \mathrm{~m}$ survey rod.

Prior to the total-station survey, GPS-RTK is typically used to acquire the accurate locations of the instrument and benchmark, from which the azimuth of survey lines can be computed. The instrument and benchmark points are usually established perpendicular to the shore line in order to obtain a cross-shore beach profile. Two orange cones visible to the rod-person are set on the survey line to help the rod-person to remain on the survey line (Figure 3). This is much more efficient than having the instrument person direct the rod-person to stay on line, although slight error may be introduced by the visual estimate of the rod-person. The positions of the instrument and benchmark are established by knocking short wood sticks or PVC pipes into the sand, typically in the dune field, where it is far away from anthropogenic disturbance and has low odds of being eroded away. These two semi-permanently established points allow for subsequent surveys to re-occupy the same line for temporal comparisons. It is important to note that the elevation of the benchmark needs to be stable and carefully measured using GPS-RTK, as it provides elevation control for the entire survey line and for temporal comparisons.

When executing the beach survey, the total station typically requires three input parameters as follows: (1) the location of the instrument in order to specify where the total survey station is placed; 
(2) the azimuth of the survey line-based on these two parameters, the location of the survey points can be computed using its angle and distance with respect to the position of the benchmark, which is automatically calculated by the internal processor of most modern total station-and lastly; (3) the height of the instrument and length of the survey rod. The first measurement is typically a "backshot" to the benchmark. It is important to compare the total station readings to the known benchmark location and elevation. This ensures that no mistakes are made during the setup of the instrument.

For this study, the surveys were conducted using NAD83 State Plane (Florida West 0902) coordinate system in meters. Other coordinate systems (e.g., UTM) can also be used. The elevations are referenced to NAVD88 in meters. NAVD88 zero is $8.2 \mathrm{~cm}$ above mean sea level (MSL) in our study area. The survey lines extend to roughly $-3 \mathrm{~m}$ NAVD88, or to the short-term closure depth in this area [30]. The usually small waves allow the rod-person to hold the rod steady in the water to ensure the accuracy of the survey data. Instead of taking survey points with uniform fixed space intervals, which may miss crucial features such as scarps or bar crests, the rod-person decides the point location with the goal of capturing all important topographic changes. Typically, denser points are taken where slope changes occur (e.g., foreshore, berm crest, sandbar etc.), and less dense points are taken where topography is uniform (e.g., flat back beach). This procedure allows efficient measurement of the beach-profile changes.

\subsection{Measurement under Special Conditions}

The procedure described in the previous section works efficiently under typical well-controlled conditions. However, complications may occur in the field. This section describes several methods to ensure efficient and accurate data collection. When the adjacent survey lines are close to each other, it is efficient to survey multiple lines with one instrument setup. This requires that the equipment be set up at a position that is visible to the nearby profiles. The instrument point can be reset at a temporal location (e.g., around the berm crest of the beach; see the position of Instrument 2 in Figure 4). This temporary instrument point can be obtained by surveying from the original instrument location. This one-setup survey of multiple lines can save considerable amount of time by eliminating several instrument setup.

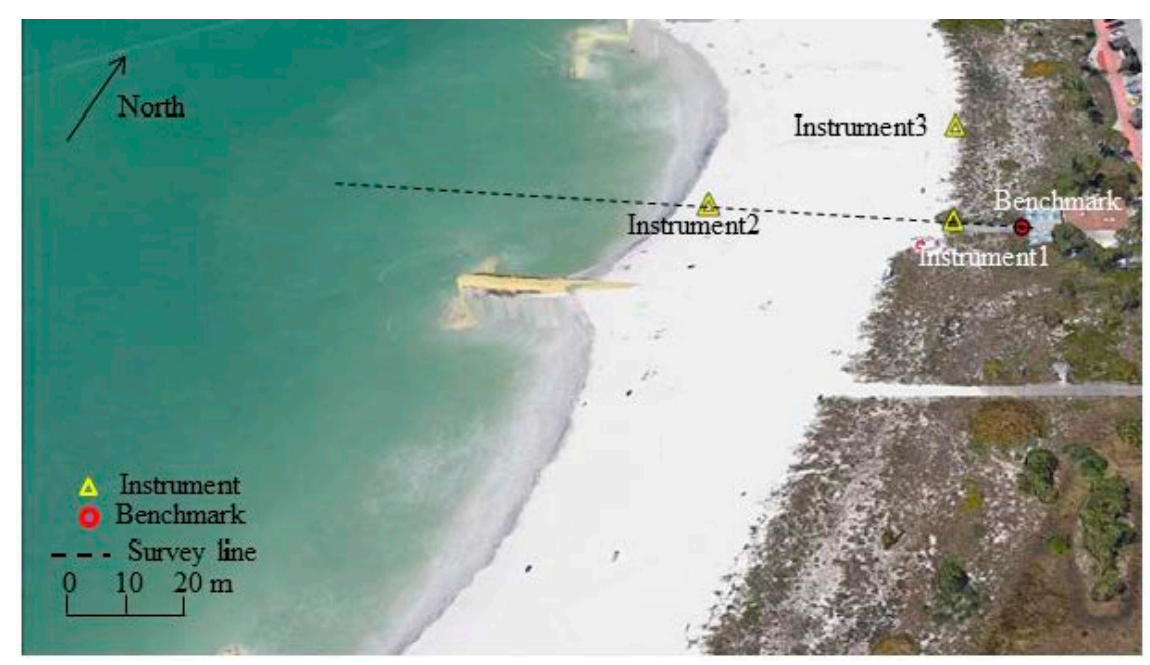

Figure 4. Example of survey line including instrument and benchmark.

Sometimes sea oats or trees grow in between the previously established instrument and benchmark points, particularly during the summer season. This blocks the line of sight from the instrument point to the benchmark point. Another complication can be caused by the occurrence of severe erosion around original instrument point which may make it impossible to set up the instrument there. In order to execute the total-station survey under these complications efficiently without re-establishing the 
line using GPS-RTK, the instrument can be set off the survey line in a place where the line of sight is not obstructed, for instance, at the location of "Instrument 3" in Figure 4. Arbitrary values for the instrument location and azimuth can be used in equipment setup. This local coordinate system can be later corrected during the data processing. In order to correct to the real earth coordinate system (e.g., NAD83), several control points (a minimum of two) need to be established using the GPS-RTK. The GPS-RTK measurements provide elevation control for the total-station survey. In addition, the GPS-RTK measured locations also provide reference points for shifting and rotating the local total-station coordinates to real-earth system. The coordinate system rotation can be conducted using the following formulas:

$$
\left[\begin{array}{l}
x^{\prime} \\
y^{\prime}
\end{array}\right]=\left[\begin{array}{cc}
\cos \theta & -\sin \theta \\
\sin \theta & \cos \theta
\end{array}\right]\left[\begin{array}{l}
x \\
y
\end{array}\right]
$$

where $\theta$ is the angle between the GPS-RTK measured line and the total station measured line. $\theta$ can be computed from the angle between the two vectors $\left(F_{1}\right.$ and $\left.F_{2}\right)$,

$$
\theta=\cos ^{-1}\left(\frac{F_{1} \cdot F_{2}}{\left|F_{1}\right|\left|F_{2}\right|}\right)
$$

It is worth noting again that both the total-station measured points and GPS-RTK measured points need to be shifted first to an origin (0, 0) before applying Equation (1). After the rotation, the origin of the rotated total-station points should be shifted again to the corresponding GPS-RTK coordinate system.

\section{Results and Discussion}

\subsection{Beach-Profile Changes in Seasonal-Annual Scale}

As the main purpose of this paper is to present an efficient method of conducting beach profile surveys using electronic total-station surveys, the analysis of the survey data (beach profiles) is not the major focus. Beach-profile changes since the completion of the most recent nourishment in August 2012 up to August 2015 were examined to illustrate the capability of total-station surveys in documenting beach evolution.

The North Sand Key project area spans a $3 \mathrm{~km}$ distance in the North Sand Key (Figure 1). The constructed berm in this project area was wider than in the areas to the south, at approximately $60 \mathrm{~m}$ wide. A divergence in longshore sediment transport occurs in this project area caused by the wave refraction over the Clearwater Pass ebb shoal [19]. The divergence of sediment transport has resulted in an erosional hotspot along a stretch of beach between R59 and R61. An example profile, R61, located within this divergence zone is shown in Figure 5. Although the beach-profiles were surveyed monthly to bi-monthly, for the clarity of the figure, only two beach profiles per year representing summer and winter seasons are presented. The beach nourishment along this section of the beach was completed in August 2012. As apparent in Figure 5, substantial beach erosion (approximately $40 \mathrm{~m}$ ) occurred during the first three years post nourishment, from August 2012 to August 2015. The entire beach-nearshore profile shifted landward, indicating erosion due to negative longshore transport gradient. Approximately two thirds of the dry beach width was lost during the three years after the nourishment. The rate of dry beach loss decreased considerably with time. This profile, R61, represents the largest profile-volume loss along this stretch of the beach. The adjacent profiles lost less volume and shoreline as compared to R61. 


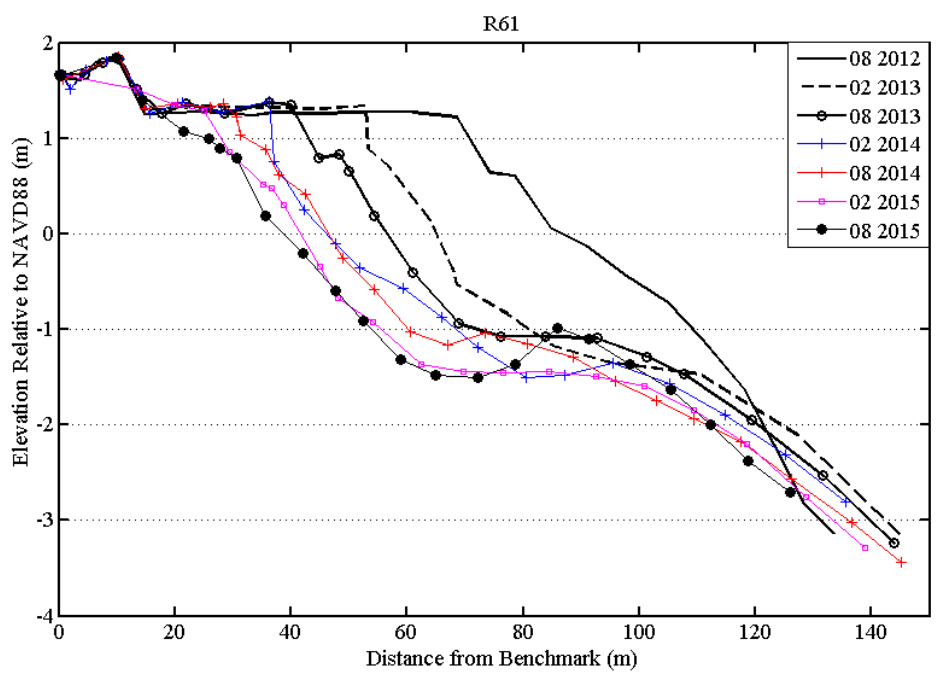

Figure 5. Example profile from the North Sand Key project area at R61.

The municipality of Belleair Shore, just south of the North Sand Key project area (Figure 1), opted out of the 2012 nourishment, providing an opportunity to monitor longshore spreading from the nourishment. An example profile, R67 located approximately $300 \mathrm{~m}$ south of the North Sand Key nourishment area, is shown in Figure 6. The beach above $1.5 \mathrm{~m}$ NAVD88 remained stable from August 2012 to August 2015. However, the lower beach and the nearshore zones gained considerable amount of sand (exact volume and shoreline gain will be discussed in detail in the following section), apparently from the nourishment just to the north. Most of the gains occurred shortly after the nourishment in 2012. A nearshore bar is rather distinctive at this profile location during most of the study period. An offshore migration of the bar, which is a typical occurrence during winter seasons, was measured during the study period from August 2012 to February 2013. The volume gain in the intertidal area may have contributed to the offshore bar migration. The bar migrated onshore at the beginning of the summer from February to August 2013, also typical of the seasonal pattern of west-central Florida. In the following winter season, the bar migrated offshore, as expected.

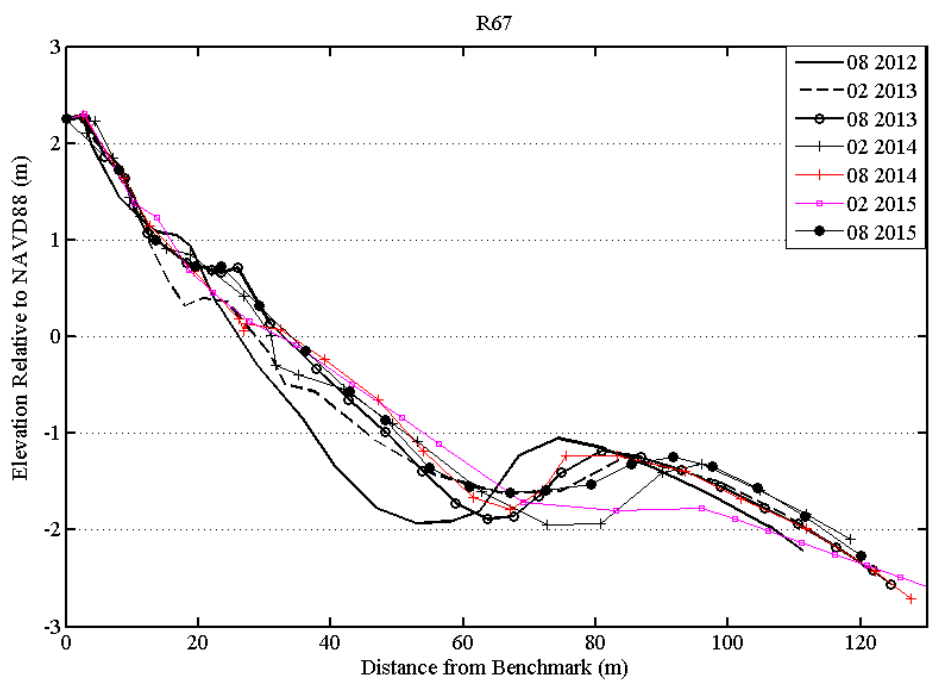

Figure 6. Example profile from the area of no fill along Belleair Shore between North Sand Key and Indian Rocks, at R67.

Indian Rocks Beach is located just south of Belleair Shore and north of the headland (Figure 1). An example profile, R75 roughly in the middle of this section, is shown in Figure 7. The Indian Rocks 
Beach area is an example representing the "typical" beach state along Pinellas County. During the winter months, the sandbar migrated offshore, followed by onshore migration during the summer months. Similar seasonal patterns have been documented by Brutsche et al. [20] and Roberts and Wang [19]. This is different from the general seasonal beach cycle [31,32], which is composed of wide gentle summer beach-berm and steep narrow winter beach.

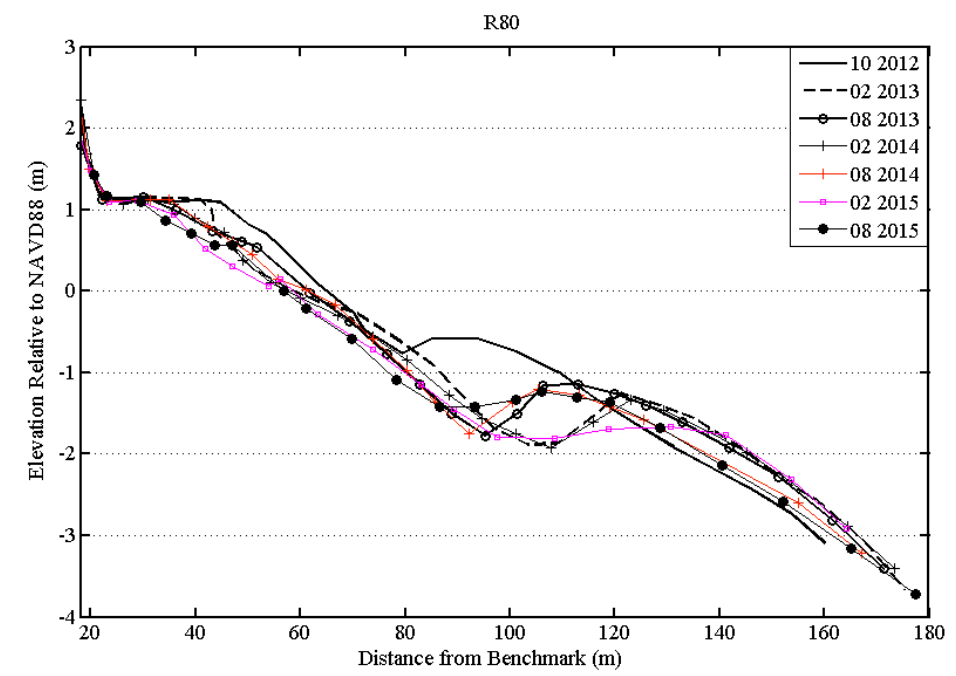

Figure 7. Example profile from Indian Rocks, R80.

The project area "Headland" is termed so due to its location on the broad headland approximately in the middle of Sand Key, reflecting a shoreline orientation change of 65 degrees from northwestto southwest-facing beaches (Figure 1). The headland project area extends from monuments R82 to $\mathrm{R} 89$ and is just over $2 \mathrm{~km}$ in length. An example profile, R84, is shown in Figure 8. The magnitude of beach-profile changes along the protruding headland is greater than that along the project area to the north. The offshore bar migration during the winter and onshore bar migration during the summer were also measured at the headland. Considerable landward berm crest (at approximately $1.5 \mathrm{~m}$ NAVD88) retreat occurred during the first a few years post the nourishment. Sand loss in the nearshore zone landward of the trough was also measured. Some of the sand eroded from the dry beach and was deposited on the nearshore bar, while some of the sand moved to the south driven by the net annual southward longshore transport.

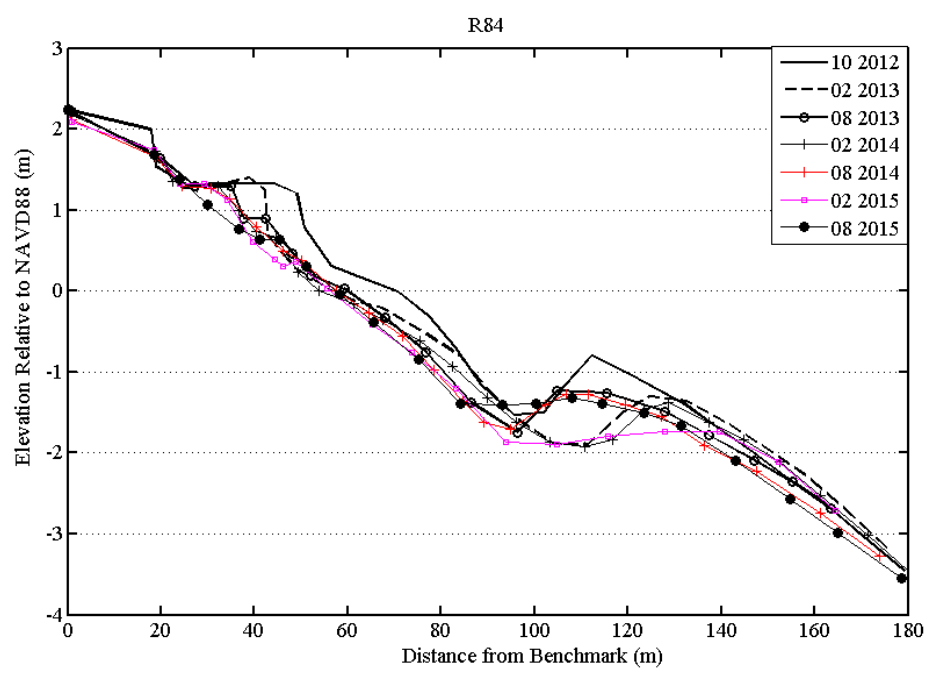

Figure 8. Example profile from the Headland, R84. 
North Redington Beach was the southern-most area nourished on Sand Key in 2012 (Figure 1). The North Redington Beach project extends from survey monuments R101 to R107, along a $2.1 \mathrm{~km}$ stretch of beach. An example profile, R105, is shown in Figure 9. The seasonal trend of offshore and onshore bar migration during the winter and summer season, respectively, was also measured at this profile. The beach at elevation of $1 \mathrm{~m}$ NAVD88 was eroded considerably during the first a few years post nourishment. The beach in the intertidal zone varied modestly without a clear trend of erosion or accretion. Overall, this profile did not have excessive sand loss, thereby suggesting that the end loss at the southern terminus of the nourishment project is not significant.

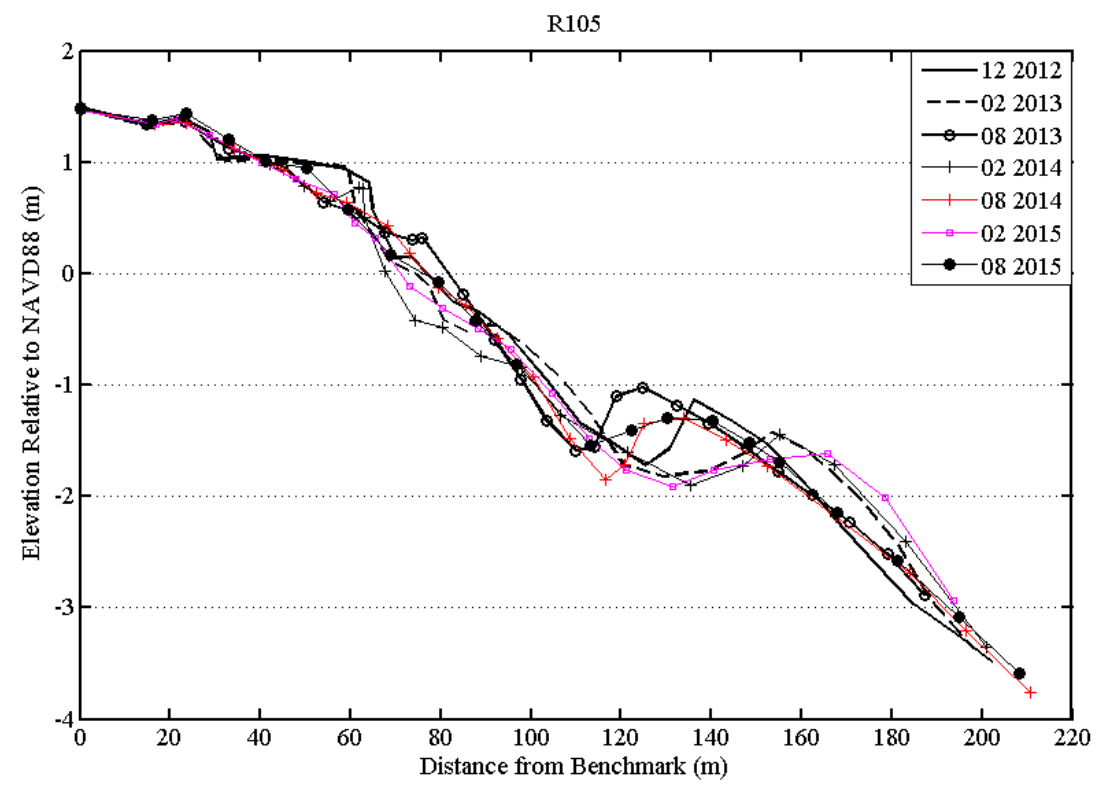

Figure 9. Example profile from North Redington Beach, R105.

\subsection{Beach-Profile Change in Storm Scale}

Several beach profiles surveyed before and after Tropical Storm Debby in 2012 are illustrated as an example of quantifying storm induced beach profile changes. Regarding storm induced beach-profile changes, beach-profiles surveyed prior and post Tropical Strom Debby in 2012 are discussed here. Although dune-beach-nearshore erosion was measured at nearly all the profile locations, different patterns of sand bar movement associated with the storm, including offshore migration, upward accretion, and onshore migration, were measured at different locations. At profile R80, located north of the headland (Figure 1), erosion was measured on the dry beach and in the nearshore region, while deposition was measured seaward of the nearshore bar, resulting in an offshore bar migration (Figure 10A). At beach profile R87, located on the headland (Figure 1), erosion in the beach-nearshore area and upward accretion of sandbar was measured (Figure 10B). The trend of bar movement was different from that north of the headland. At beach profile R105, located south of the headland (Figure 1), erosion in the beach-nearshore area and landward migration of sandbar was measured (Figure 10C). It is worth noting that most profiles mapped with the total station survey technique easily capture offshore profile convergence, as illustrated by three different profile locations within the study area. It is beyond the scope of this paper to discuss the mechanism of sandbar movement. The results on the sandbar migration are discussed in Roberts and Wang [19], Cheng et al. [33], and Cheng and Wang [34]. 

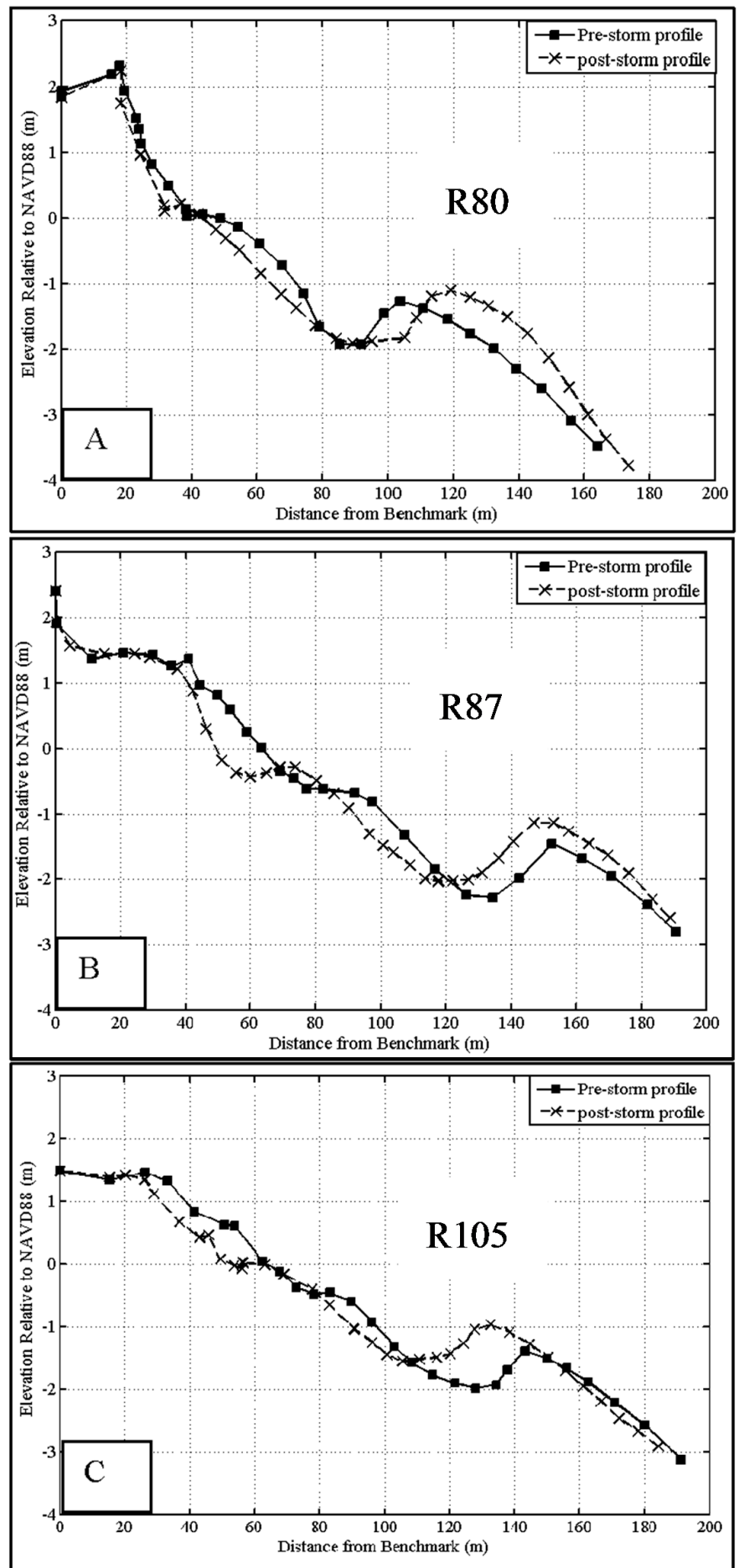

Figure 10. Pre- and post-storm surveyed beach profiles at (A) R80; (B) R87; and (C) R105.

\section{Conclusions}

Beach-profile surveys using total station have been conducted along the coast of west-central Florida for 10 years. Considerable longshore variations of beach-profile changes at a seasonal-annual scale were measured. Severe shoreline retreats occurred at an erosional hot spot at North Sand Key. The shoreline remains relatively stable at a "typical" beach profile, with bar migration in response to wave condition variations. At the storm temporal scale, various bar behaviors were measured including both onshore and offshore bar migration, as well as upward bar accretion. 
An efficient field data collection method was developed and described here. It yielded a large and valuable dataset for conducting research on the mechanisms of beach erosion/accretion and sandbar migration, among other topics. Time-series beach-profile data allow quantitative evaluation of the performance of beach nourishment projects and help to optimize beach nourishment design, which is crucial for successful coastal management.

As compared to the increasingly applied airborne LIDAR survey method, the total station survey is more labor intensive in the field and with much lower spatial resolution. The various details discussed above, such as using marker cones to help the rod-person to follow the survey line and surveying multiple lines with one instrument setup, are aimed at improving the survey efficiency and subsequently the spatial coverage and resolution. Procedures of coordinate system rotation are discussed for the case in which a local coordinate system has to be used in field data collection.

The main advantages of total station survey include: (1) the ease of planning that allows for the efficient execution of storm-related data collection; (2) low costs that can lead to high temporal coverage and resolution; and (3) accurate data, especially in the dynamic surf zone, for detailed analysis of beach changes. The above advantages make the total station survey method an ideal tool for graduate research. Total-station survey is a practical and accurate method for documenting beach changes, especially for low wave-energy coasts.

Acknowledgments: This study was funded by Pinellas County, Florida and the University of South Florida. We also would like to thank several graduate and undergraduate students for their assistance in field data collection.

Author Contributions: Jun Cheng conceived the research, conducted the field measurement, analyzed the data and wrote the article. Ping Wang designed the research, reviewed the results and the article, Qiandong Quo helped in the discussion of the remote sensing technology in coastal surveying.

Conflicts of Interest: The authors declare no conflict of interest.

\section{References}

1. Leatherman, S.P.; Zhang, K.; Douglas, B.C. Sea level rise shown to drive coastal erosion. Eos Trans. Am. Geophys. Union 2000, 81, 55-57. [CrossRef]

2. Zhang, K.Q.; Douglas, B.C.; Leatherman, S.P. Global warming and coastal Erosion. Clim. Chang. 2004, 64, 41-58. [CrossRef]

3. Van Rijn, L.C. Coastal erosion and control. Ocean Coast. Manag. 2011, 54, 867-887. [CrossRef]

4. Dean, R.G. Beach Nourishment, Theory and Practice; World Scientific: Singapore, 2002.

5. NRC (National Research Council: Committee on Beach Nourishment, Protection). Beach Nourishment and Protection, Marine Board, Commission on Engineering and Technical Systems; National Academy Press: Washington, DC, USA, 1995.

6. Ruggiero, P.; Walstra, D.J.R.; Gelfenbaum, G.; Van Ormondt, M. Seasonal-scale nearshore morphological evolution: Field observations and numerical modeling. Coast. Eng. 2009, 56, 1153-1172. [CrossRef]

7. Lee, J.M.; Park, J.Y.; Choi, J.Y. Evaluation of sub-aerial topographic surveying techniques using Total Station and RTK-GPS for applications in macrotidal sand beach environment. J. Coast. Res. 2013, 65, 535-540. [CrossRef]

8. Holman, R.A.; Stanley, J. The history and technical capabilities of Argus. Coast. Eng. 2007, 54, 477-491. [CrossRef]

9. Saye, S.; van der Wal, D.; Pye, K. Beach-dune morphological relationships and erosion/accretion: An investigation at five sites in England and Wales using lidar data. Geomorphology 2005, 72, 128-155. [CrossRef]

10. Turner, I.L.; Harley, M.D.; Drummond, C.D. UAVs for coastal surveying. Coast. Eng. 2016, 114, $19-24$. [CrossRef]

11. Stockdon, H.F.; Holman, R.A. Estimation of wave phase speed and nearshore bathymetry from video imagery. J. Geophys. Res. 2000, 105, 22015-22033. [CrossRef]

12. Lippmann, T.C.; Holman, R.A. The spatial and temporal variability of sand bar morphology. J. Geophys. Res. 1990, 95, 11575-11590. [CrossRef] 
13. Cheng, J.; Wang, P. Extracting Turbulence under Breaking Waves in the Surf Zone. J. Waterw. Port Coast. Ocean Eng. 2015, 141, 06015003. [CrossRef]

14. Kingston, K.; Ruessink, B.G.; Van Enckevort, I.M.J.; Davidson, M.A. Artificial neural network correction of remotely sensed sandbar location. Mar. Geol. 2000, 169, 137-160. [CrossRef]

15. Stockdon, H.F.; Sallenger, A.H.; List, J.H.; Holman, R.A. Estimation of shoreline position and change using airborne topographic lidar data. J. Coast. Res. 2002, 18, 502-513.

16. James, M.R.; Ilic, S.; Ruzic, I. Measuring 3D coastal change with a digital camera. In Proceedings of the 7th International Conference on Coastal Dynamics 2013, Arcachon, France, 24-28 June 2013; Bonneton, P., Garlan, T., Sottolichio, A., Castelle, B., Eds.; Bordeaux University: Bordeaux, France, 2013; pp. 893-904.

17. Delacourt, C.; Allemand, P.; Jaud, M.; Grandjean, P.; Deschamps, A.; Ammann, J.; Cuq, V. DRELIO: An unmanned helicopter for imaging coastal areas. J. Coast. Res. 2009, 56, 1489-1493.

18. Elko, N.A.; Wang, P. Immediate profile and planform evolution of a beach nourishment project with hurricane influences. Coast. Eng. 2007, 54, 49-66. [CrossRef]

19. Roberts, T.M.; Wang, P. Four-year performance and associated controlling factors of several beach nourishment projects along three adjacent barrier island, west-central Florida, USA. Coast. Eng. 2012, 70, 21-39. [CrossRef]

20. Brutsche, K.E.; Wang, P.; Beck, T.M.; Rosati, J.D.; Legault, K.R. Morphological evolution of a submerged artificial nearshore berm along a low-wave microtidal coast, Fort Myers Beach, west-central Florida, USA. Coast. Eng. 2014, 91, 29-44. [CrossRef]

21. Cheng, J.; Wang, P. Measuring and modeling beach-profile response to tropical storm Debby, west central Florida. In Proceedings of the Coastal Sediments 2015, San Diego, CA, USA, 11-15 May 2015.

22. Hanson, H.; Brampton, A.; Capobianco, M.; Dette, H.H.; Hamm, L.; Laustrup, C.; Lechuga, A.; Spanhoff, R. Beach nourishment projects, practices, and objectives-A European overview. Coast. Eng. 2002, 47, 81-111. [CrossRef]

23. Work, P.; Dean, R.G. Assessment and prediction of beach-nourishment evolution. J. Waterw. Port Coast. Ocean Eng. 1995, 121, 182-189. [CrossRef]

24. Wang, P.; Kirby, J.H.; Haber, J.D.; Horwitz, M.H.; Knorr, P.O.; Krock, J.R. Morphological and Sedimentological Impacts of Hurricane Ivan and Immediate Poststorm Beach Recovery along the Northwestern Florida Barrier-Island Coasts. J. Coast. Res. 2006, 22, 1382-1402. [CrossRef]

25. Wang, P.; Roberts, T.M. Volume and Shoreline Changes along Pinellas County Beaches during Tropical Storm Debby; Tropical Strom Debby-Impact Report; Pinellas County, FL, USA, 2012.

26. Davis, R.A.; Barnard, P. Morphodynamics of the barrier-inlet system, west-central Florida. Mar. Geol. 2003, 200, 77-101. [CrossRef]

27. Gibeaut, J.C.; Davis, R.A. Statistical Geomorphic classification of ebb-tidal deltas along the west-central Florida coast. J. Coast. Res. 1993, 18, 165-184.

28. Wang, P.; Beck, T.M. Morphodynamics of an anthropogenically altered dual-inlet system: John's Pass and Blind Pass, west-central Florida, USA. Mar. Geol. 2012, 291, 162-175. [CrossRef]

29. Walton, T.L. Littoral Drift Estimates along the Coastline of Florida; Florida Sea Grant Report No. 13; University of Florida: Gainesville, FL, USA, 1976.

30. Wang, P.; Davis, R.A. Depth of closure and the equilibrium beach profile-A case study from Sand key, west-central Florida. Shore Beach 1999, 67, 33-42.

31. Komar, P.D. Beach Processes and Sedimentation, 2nd ed.; Prentice Hall: Upper Saddle River, NJ, USA, 1998.

32. Roberts, T.M.; Wang, P.; Puleo, J.A. Storm-driven cyclic beach morphodynamics of a mixed sand and gravel beach along the Mid-Atlantic Coast, USA. Mar. Geol. 2013, 346, 403-421. [CrossRef]

33. Cheng, J.; Wang, P.; Smith, R.E. Hydrodynamic conditions associated with an onshore migrating and stable sandbar. J. Coast. Res. 2016, 32, 153-163. [CrossRef]

34. Cheng, J.; Wang, P. Event to seasonal scale sandbar variability and equilibrium along a low-wave energy microtidal Coast, west-central Florida, USA. Cont. Shelf Res. 2016, in review.

(C) 2016 by the authors; licensee MDPI, Basel, Switzerland. This article is an open access article distributed under the terms and conditions of the Creative Commons Attribution (CC-BY) license (http://creativecommons.org/licenses/by/4.0/). 